\title{
Effects of Gold Substrates on the Intrinsic and Extrinsic Activity of High-Loading Nickel-Based Oxyhydroxide Oxygen Evolution Catalysts
}

Chakthranont, Pongkarn; Kibsgaard, Jakob; Gallo, Alessandro; Park, Joonsuk; Mitani, Makoto; Sokaras, Dimosthenis; Kroll, Thomas; Sinclair, Robert; Mogensen, Mogens Bjerg; Jaramillo, Thomas F.

\section{Published in:}

A C S Catalysis

Link to article, DOI:

10.1021/acscatal.7b01070

Publication date:

2017

Document Version

Peer reviewed version

Link back to DTU Orbit

Citation (APA):

Chakthranont, P., Kibsgaard, J., Gallo, A., Park, J., Mitani, M., Sokaras, D., Kroll, T., Sinclair, R., Mogensen, M. B., \& Jaramillo, T. F. (2017). Effects of Gold Substrates on the Intrinsic and Extrinsic Activity of High-Loading Nickel-Based Oxyhydroxide Oxygen Evolution Catalysts. A C S Catalysis, 7, 5399-5409. https://doi.org/10.1021/acscatal.7b01070

\section{General rights}

Copyright and moral rights for the publications made accessible in the public portal are retained by the authors and/or other copyright owners and it is a condition of accessing publications that users recognise and abide by the legal requirements associated with these rights.

- Users may download and print one copy of any publication from the public portal for the purpose of private study or research.

- You may not further distribute the material or use it for any profit-making activity or commercial gain

- You may freely distribute the URL identifying the publication in the public portal 


\section{Effects of Gold Substrates on the Intrinsic and}

\section{Extrinsic Activity of High-Loading Nickel-Based}

\section{Oxyhydroxide Oxygen Evolution Catalysts}

Pongkarn Chakthranont ${ }^{1}$, Jakob Kibsgaard ${ }^{1,2,3}$, Alessandro Gallo ${ }^{1,2}$, Joonsuk Park ${ }^{4}$, Makoto

Mitani $^{1}$, Dimosthenis Sokaras 5 , Thomas Kroll ${ }^{5}$, Robert Sinclair ${ }^{4}$, Mogens B. Mogensen ${ }^{6}$, and

Thomas F. Jaramillo ${ }^{1,2 *}$

AUTHOR ADDRESS

${ }^{1}$ SUNCAT Center for Interface Science and Catalysis, Department of Chemical Engineering, Stanford University, Stanford, California 94305, United States.

${ }^{2}$ SUNCAT Center for Interface Science and Catalysis, SLAC National Accelerator Laboratory,

Menlo Park, California 94025, United States.

${ }^{3}$ Department of Physics, Technical University of Denmark, DK-2800 Kongens Lyngby,

Denmark.

${ }^{4}$ Department of Materials Science and Engineering, Stanford University, 496 Lomita Mall, California 94305, United States 
${ }^{5}$ Stanford Synchrotron Radiation Lightsource, SLAC National Accelerator Laboratory, 2575

Sand Hill Road, Menlo Park, 94025, California, United States

${ }^{6}$ Department of Energy Conversion and Storage, Technical University of Denmark, Frederiksborgvej 399, DK-4000 Roskilde, Denmark

KEYWORDS: substrate effects, oxygen evolution reaction, nickel oxyhydroxide, nickel cerium, nickel iron, loading dependence, conductivity, electrochemical impedance spectroscopy

\section{ABSTRACT}

We systematically investigate the effects of Au substrates on the oxygen evolution activities of cathodically electrodeposited nickel oxyhydroxide (NiOOH), nickel-iron oxyhydroxide $(\mathrm{NiFeOOH})$, and nickel-cerium oxyhydroxide $(\mathrm{NiCeOOH})$ at varying loadings from $0-2000 \mathrm{nmol}$ of metal $/ \mathrm{cm}^{2}$. We determine that the geometric current densities, especially at higher loadings, were greatly enhanced on $\mathrm{Au}$ substrates: $\mathrm{NiCeOOH} / \mathrm{Au}$ reached $10 \mathrm{~mA} / \mathrm{cm}^{2}$ at $259 \mathrm{mV}$ overpotential, and $\mathrm{NiFeOOH} / \mathrm{Au}$ achieved $140 \mathrm{~mA} / \mathrm{cm}^{2}$ at $300 \mathrm{mV}$ overpotential, which were much greater than those of the analogous catalysts on graphitic carbon (GC) substrates. By performing a loading quantification using both inductively coupled plasma optical emission spectrometry and integration of the $\mathrm{Ni}^{2+/ 3+}$ redox peak, we show that the enhanced activity is predominantly caused by the stronger physical adhesion of catalysts on Au. Further characterizations using impedance spectroscopy and in situ X-ray absorption spectroscopy revealed that the catalysts on $\mathrm{Au}$ exhibited lower film resistances and higher number of electrochemically active metal sites. We attribute this enhanced activity to a more homogeneous electrodeposition on $\mathrm{Au}$, yielding catalyst films with very high geometric current densities on flat 
substrates. By investigating the mass and site specific activities as a function of loading, we bridge the practical geometric activity to the fundamental intrinsic activity.

\section{Introduction}

The oxygen evolution reaction (OER) is the most important counter reaction for a large number of electrochemical energy conversions in aqueous environment, e.g. for $\mathrm{H}_{2}$ production from water splitting, $\mathrm{CO}_{2}$ reduction to hydrocarbons and oxygenates, $\mathrm{NH}_{3}$ synthesis from $\mathrm{N}_{2}$ reduction, $\mathrm{H}_{2} \mathrm{O}_{2}$ generation from $\mathrm{O}_{2}$, and charging of metal-air batteries, all of which are promising for renewable energy storage and/or conversion to fuels and chemicals. ${ }^{1-5}$ Depending on the application, the required current density for the reaction can vary by several orders of magnitude. For example, in photoelectrochemical water splitting, a geometric current density of $10 \mathrm{~mA} / \mathrm{cm}^{2}$ corresponds to approximately $10 \%$ solar-to-hydrogen efficiency and is considered a standard performance metric that is also used for the OER research. ${ }^{6}$ However, for alkaline and proton-exchange membrane electrolyzers, the operating current densities are much higher, 0.5 and $2 \mathrm{~A} / \mathrm{cm}^{2}$, respectively. ${ }^{7-8}$ Despite decades of research, a significant overpotential is required to drive the sluggish kinetics of the OER and only a few reports have demonstrated catalysts that achieve $500 \mathrm{~mA} / \mathrm{cm}^{2}$ at moderate overpotentials of less than $300 \mathrm{mV} \cdot{ }^{9-10}$ The lack of highly active OER catalysts on the geometric scale imposes a bottleneck in the commercialization of the electrochemical devices. ${ }^{11}$

Catalysts that can achieve high geometric activity must have both high intrinsic activity and a large number of active sites. The intrinsic activity of the catalyst depends on the binding energy of the OER intermediates, which can be tuned by chemical and electronic modifications of the active sites. ${ }^{12}$ The number of active sites can be increased by loading more catalyst and/or nanostructuring to increase the electrochemically active surface area. ${ }^{13-14}$ The challenge in attaining high geometric 
activity arises from the entanglement between the intrinsic activity and the number of active sites of a catalyst. As the number of active sites increases, the intrinsic activity per site often decreases due to ohmic losses from increased loading or mass transport limitations caused by nanostructuring. ${ }^{15}$ Hence, scaling up a catalyst for electrolyzer applications that operate at high geometric current density requires optimizing both intrinsic activity and number of active sites. This can only be accomplished with a thorough understanding of how intrinsic activity changes as a function of loading.

Nickel oxyhydroxide $(\mathrm{NiOOH})$-based catalysts are promising materials that can potentially achieve high geometric activity due to the outstanding intrinsic activity and the large intrinsic surface area. ${ }^{16-17}$ Even though the intrinsic activity of $\mathrm{NiOOH}$ is low, it can be greatly improved by alloying with Fe or Ce. ${ }^{18}$ Specifically, nickel-iron oxyhydroxide (NiFeOOH) and nickel-cerium oxyhydroxide $(\mathrm{NiCeOOH})$ catalysts have proven to be active and robust, achieving $10 \mathrm{~mA} / \mathrm{cm}^{2}$ at overpotentials well below $300 \mathrm{mV} \cdot{ }^{19-21} \mathrm{NiOOH}$-based catalysts also exhibit a large surface area due to its layered structure, allowing this catalyst to behave to some extend as a "volume" catalyst where the overall activity scales with the mass loading. ${ }^{22-23}$ Furthermore, a high surface area support, such as nickel foam, has been proven effective for increasing the surface area of $\mathrm{NiOOH}-$ based catalysts without significant mass transport limitations. ${ }^{24}$ Nevertheless, there remains significant room for improvement especially at the high geometric current densities.

One strategy that can potentially improve the intrinsic activity and increase the number of active sites of NiOOH-based catalysts is by favorable support interactions. There is no standardized substrate for OER testing. Various supports have been used such as glassy carbon (GC), fluorine doped tin oxide (FTO), indium doped tin oxide (ITO), Pt, Pd, carbon paper, nickel foam, and $\mathrm{Au}^{25-}$ ${ }^{32}$ It has been widely reported that $\mathrm{Au}$ substrates can enhance the activity of submonolayer 
transition metal oxide OER catalysts such as $\mathrm{Ni}, \mathrm{Co}, \mathrm{Fe}$, and $\mathrm{Mn}$ oxides either by electronic structure modification of the active sites or by direct participation in the reaction. ${ }^{27-28,33-36}$ Recently, we have also discovered that Au substrates drastically enhance the geometric activity of $\mathrm{NiOOH}$-based catalysts, especially $\mathrm{NiCeOOH}$ synthesized by cathodic electrodeposition, which can be fabricated to a highly active and stable OER electrode. ${ }^{19}$ The intrinsic activity at various loadings of $\mathrm{NiFeOOH}$ deposited on $\mathrm{Au}$ has been investigated, ${ }^{22}$ there is much to be learned about the effect of Au substrates on the activity of high loading catalysts, especially because high loading systems are more likely to be implemented in practical devices.

In this work, we present a systematic investigation of the effect of two flat substrates, Au and GC, on the geometric activity, intrinsic activity, and number of active sites of $\mathrm{NiOOH}, \mathrm{NiFeOOH}$, and $\mathrm{NiCeOOH}$ OER catalysts. We demonstrate that the NiOOH-based catalysts on Au performed exceptionally better relative to those on GC substrate, achieving much higher geometric current densities at high catalyst loadings. Specifically, $\mathrm{NiCeOOH} / \mathrm{Au}$ was able to achieve $10 \mathrm{~mA} / \mathrm{cm}^{2}$ at overpotential as low as $259 \mathrm{mV}$. At $300 \mathrm{mV}$ overpotential, NiFeOOH/Au performed the best, achieving a geometric current density of $140 \mathrm{~mA} / \mathrm{cm}^{2}$ in $1 \mathrm{M} \mathrm{Fe}$-free $\mathrm{NaOH}$. To understand the origins of the effect of $\mathrm{Au}$ and GC substrates, we employed inductively coupled plasma, integration of Ni redox peak, electrochemical impedance spectroscopy, in situ X-ray absorption spectroscopy, and cross-sectional transmission electron microscopy. We attribute the superior geometric activity to the homogeneous distribution of catalyst deposited on Au compared to GC substrate, not to enhanced intrinsic activity. The use of Au substrates allows for (1) a greater amount of catalyst physically adhered and electrically connected, (2) a lower film resistivity, and (3) a higher number of electrochemically active sites. These effects are critical to the performance 
of $\mathrm{NiOOH}, \mathrm{NiFeOOH}$, and especially $\mathrm{NiCeOOH}$, where over 6-fold increases in geometric current density at $300 \mathrm{mV}$ overpotential can be achieved on Au compared to GC substrate.

\section{Experimental Section}

\subsection{Synthesis of $\mathrm{NiOOH}, \mathrm{NiFeOH}$, and $\mathrm{NiCeOOH}$}

$\mathrm{NiOOH}, \mathrm{NiFeOOH}$, and $\mathrm{NiCeOOH}$ were synthesized by electrodeposition from metal nitrate aqueous solutions using $\mathrm{Ni}\left(\mathrm{NO}_{3}\right)_{2} \cdot 6 \mathrm{H}_{2} \mathrm{O}\left(99.9985 \%\right.$, Strem Chemicals), $\mathrm{Fe}\left(\mathrm{NO}_{3}\right)_{3} \cdot 9 \mathrm{H}_{2} \mathrm{O}(99.95 \%$, Sigma-Aldrich), and $\mathrm{Ce}\left(\mathrm{NO}_{3}\right)_{3} \cdot 6 \mathrm{H}_{2} \mathrm{O}$ (99.99\%, Sigma-Aldrich). The GC disk substrates (0.196 $\mathrm{cm}^{2}$ geometric area, SIGRADUR G HTW Hochtemperatur-Werkstoffe GmbH) were polished and sonicated sequentially in acetone and isopropanol to clean off organic contaminants. The cleaned substrates were further soaked in $10 \%$ nitric acid to leech metal contaminants. The Au substrates were prepared by e-beam evaporating $10 \mathrm{~nm}$ of Ti as a sticking layer and $100 \mathrm{~nm}$ of $\mathrm{Au}$ on the cleaned GC disks. Electrodeposition was carried out in a three-electrode configuration with a rotating disk electrode (RDE) setup using a carbon rod counter electrode and a $\mathrm{Ag} / \mathrm{AgCl}$ reference electrode. The glass container, the counter electrode, the reference electrode, and the Teflon holder for the GC disk were prewashed in 10\% nitric acid to mitigate metal contamination. The deposition electrolytes were $100 \mathrm{mM} \mathrm{Ni}$ for $\mathrm{NiOOH}, 95 \mathrm{mM} \mathrm{Ni}$ and $5 \mathrm{mM}$ Fe for $\mathrm{NiFeOOH}$, and $95 \mathrm{mM} \mathrm{Ni}$ and $5 \mathrm{mM} \mathrm{Ce}$ for $\mathrm{NiCeOOH}$. The deposition current of $-16 \mathrm{~mA} / \mathrm{cm}^{2}$ was passed at varying deposition times from $1-30 \mathrm{~s}$ at a rotating speed of $400 \mathrm{rpm}$, similar to the previous reported work

(see further discussion in the SI) ${ }^{18-19}$ The average deposition potentials for GC and Au substrates were -1.25 and $-0.95 \mathrm{~V}$ and vs. $\mathrm{Ag} / \mathrm{AgCl}$, respectively (Figure S1) and the ohmic resistance was $\sim 50 \mathrm{ohm}$ as measured by impedance spectroscopy at $100 \mathrm{kHz}$. The deposited catalysts were rinsed 
with water and dried in an air stream, and then they were tested for the electrochemical performance immediately to minimize further oxidation in air.

\subsection{Electrochemical Characterizations and Analysis}

Electrochemical evaluation was performed in a 1 M Fe-free sodium hydroxide $(99.99 \%$, SigmaAldrich) electrolyte which was purified according to a previously reported procedure ${ }^{37}$ using $\mathrm{Ni}(\mathrm{OH})_{2}$ to precipitate trace Fe. The electrochemical setup consisted of a polypropylene electrochemical cell, a Pt wire counter electrode, and a Teflon $\mathrm{Hg} / \mathrm{HgO}$ reference electrode $(\mathrm{CH}$ Instruments), all of which were cleaned in $10 \%$ nitric acid to mitigate Fe contamination. The reference potential scale was calibrated to the reversible hydrogen electrode (RHE) using a Pt wire as the working electrode in a $\mathrm{H}_{2}$-saturated electrolyte; all potentials are reported on the RHE scale. The electrochemical measurement consisted of an ohmic drop determination by electrochemical impedance spectroscopy (EIS) at open circuit potential and a $100 \mathrm{kHz}$ AC-modulation of $10 \mathrm{mV}$ amplitude. Compensating for $85 \%$ resistance, a cyclic voltammogram (CV) was scanned at 10 $\mathrm{mV} / \mathrm{s}$ from $1.23 \mathrm{~V}$ vs RHE to $1.70,1.55$, and $1.60 \mathrm{~V}$ vs RHE for $\mathrm{NiOOH}, \mathrm{NiFeOOH}$, and $\mathrm{NiCeOOH}$, respectively. The CV was followed by an EIS scan from $200 \mathrm{kHz}$ to $20 \mathrm{mHz}$ at the most anodic potential from the CV scan of each catalyst. Each CV was further compensated for the last $15 \%$ using the ohmic resistance value from the anodic EIS. The oxidation charge (area under the oxidation peak) were calculated from the $85 \%$ compensated $\mathrm{CV}$, and the OER activity was obtained from the $100 \%$ compensated CV. Error analysis at each different condition was conducted by synthesizing and testing $2-5$ repeat samples.

The impedance data was fitted by a nonlinear least-squares solver function in MATLAB to extract the circuit parameters: electrolyte resistance $\left(R_{\mathrm{e}}\right)$, film resistance $\left(R_{\mathrm{f}}\right)$, film constant phase element 
$\left(Q_{\mathrm{f}}, a_{\mathrm{f}}\right)$, charge transfer resistance $\left(R_{\mathrm{ct}}\right)$, and double layer constant phase element ( $\left.Q_{\mathrm{dl}}, a_{\mathrm{dl}}\right)$. The parameters associated with a constant phase element were then converted to an average capacitance (see SI for detailed calculation). ${ }^{38}$ The Tafel slope was also calculated from the $R_{\mathrm{ct}}$ and the current recorded during EIS measurement. Although mass transport could play a role in the case of thick oxide films, the Warburg impedance was neglected in this study for the simplicity of the model and the analysis. The $\mathrm{R}^{2}$ values of all fits were all greater than 0.95 .

\subsection{Physical and Chemical Characterizations}

The mass loading and elemental composition of both freshly prepared and electrochemically tested samples of $\mathrm{NiOOH}, \mathrm{NiFeOOH}$, and $\mathrm{NiCeOOH}$ were determined using inductively coupled plasma optical emission spectrometry (ICP-OES) (Thermo Scientific ICAP 6300 Duo View Spectrometer). Each set of catalyst films (9 different loadings for both Au and GC substrates) was dissolved in aqua regia ( 3 parts $\mathrm{HCl}: 1$ part $\mathrm{HNO}_{3}$ ) overnight before dilution to $5 \%$ acid with Millipore water. $\mathrm{Ni}, \mathrm{Ce}, \mathrm{Au}$, and $\mathrm{Fe}$ standards (Sigma-Aldrich) were used for calibration.

The oxidation state of $\mathrm{NiCeOOH}$ was further investigated by in situ high energy resolution fluorescence detected X-ray absorption spectroscopy (HERFD-XAS). The measurements were carried out at the Stanford Synchrotron Radiation Lightsource (SSRL). Both incident beam and fluorescence entered and exited through the silicon nitride window or GC wafer at the back of the electrodes at an angle of $\sim 45^{\circ}$, with no penetration of electrolyte necessary. HERFD-XAS measurements were made with the high resolution spectrometer at the SSRL beamline $6-2 .{ }^{39}$ The incident energy was selected using a double-crystal monochromator with $\operatorname{Si}(111)$ crystals for measurements at the Ni K-edge. A Rowland circle spectrometer $(\mathrm{R}=1 \mathrm{~m})$ was aligned to the peaks of the Ni $\mathrm{K} \alpha$ lines. The $\mathrm{Ni} \mathrm{K} \alpha$ emission at $7478 \mathrm{eV}$ was collected using three spherically bent 
$\operatorname{Si}(620)$ crystals at a Bragg angle of $74.9^{\circ}$. The combined resolution of the spectrometer and monochromator was $1.3 \mathrm{eV}$ for measurements at the Ni K-edge. HERFD XAS scans were treated by subtracting a constant background (typically $\sim 25$ counts/s) and normalized to an edge-jump of 1.

$\mathrm{NiOOH}$ and $\mathrm{NiCeOOH}$ were deposited for $1 \mathrm{~s}$ on $\mathrm{GC}$ wafers and $\mathrm{Au}$ coated $\mathrm{Si}_{3} \mathrm{~N}_{4}$ windows and the catalysts were illuminated with X-ray from the back side through the substrate. ${ }^{35}$ The XAS spectra were obtained under applied bias at 1.23 and $1.65 \mathrm{~V}$ vs RHE.

The surface chemical composition was investigated by X-ray photoelectron spectroscopy (XPS), and the crystallinity was assessed by X-ray diffraction (XRD) similar to previous work (not shown here). ${ }^{19}$ The morphology of the $\mathrm{NiCeOOH}$ specifically was characterized by atomic force microscopy (AFM) in a noncontact mode (Park XE-70).

Cross-sectional transmission electron microscopy (TEM) samples were prepared using Focus Ion Beam (FIB, FEI Helios nanolab 600i) lift-off technique employing $30 \mathrm{kV} \mathrm{Ga}+$ ion beam. Highresolution TEM imaging and scanning TEM energy dispersive x-ray spectroscopy (STEM-EDS) mapping were acquired using aberration-corrected TEM (FEI Titan ETEM 80-300) at $300 \mathrm{kV}$ accelerating voltage.

\section{Results and Discussion}

\subsection{Substrate Effects on the Geometric Activities of $\mathrm{NiOOH}, \mathrm{NiFeOOH}$, and $\mathrm{NiCeOOH}$}


(a)
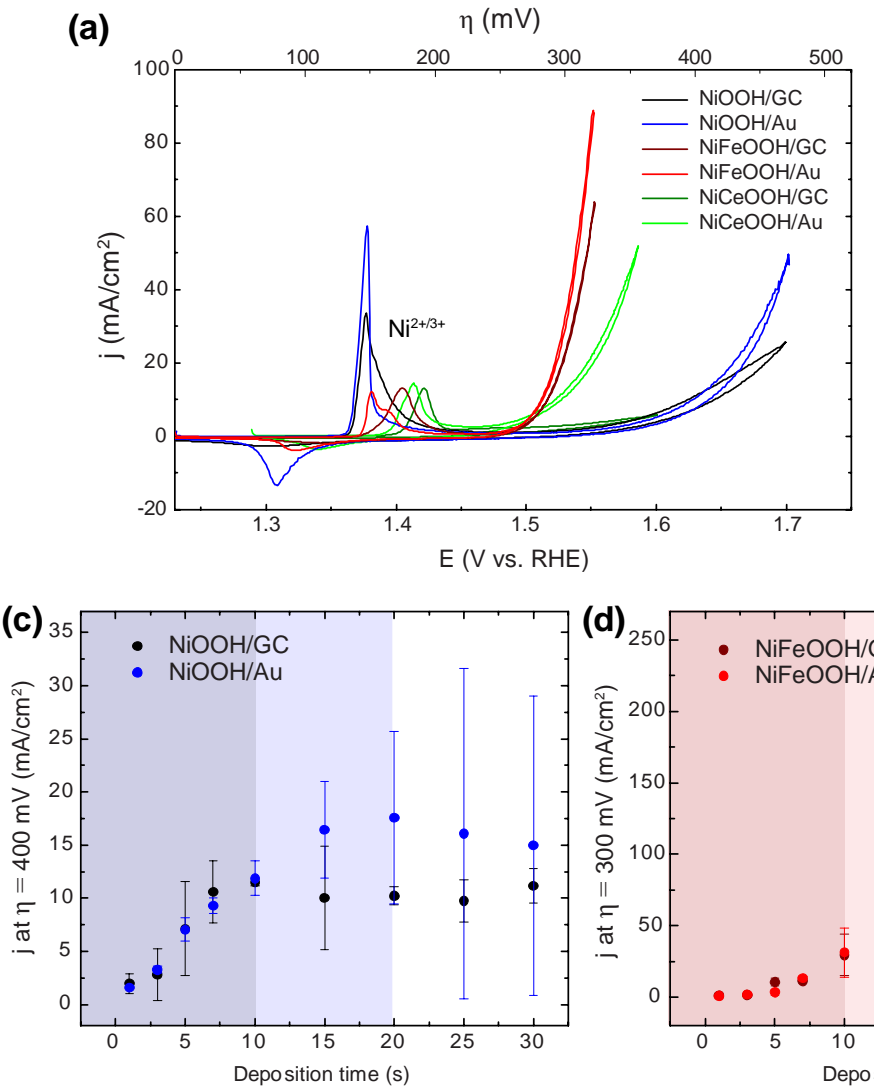
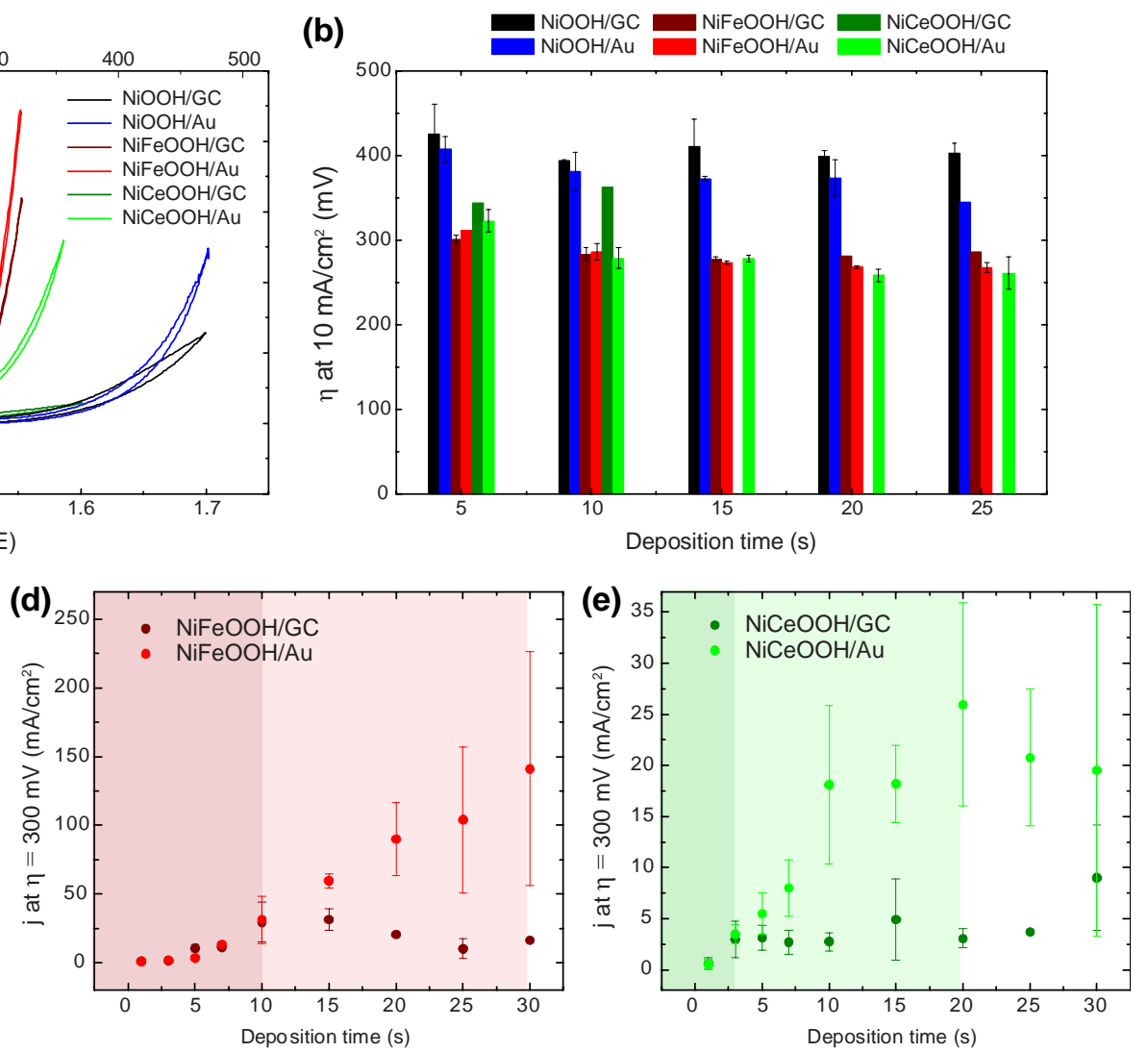

Figure 1. (a) $\mathrm{CV}$ s of $\mathrm{NiOOH}, \mathrm{NiFeOOH}$, and $\mathrm{NiCeOOH}$ on $\mathrm{GC}$ and $\mathrm{Au}$ substrates that were cathodically deposited at $-16 \mathrm{~mA} / \mathrm{cm}^{2}$ for $10 \mathrm{~s}$. (b) Overpotentials ( $\mathrm{n}$ ) required to achieve 10 $\mathrm{mA} / \mathrm{cm}^{2}$ geo for catalysts with varying deposition time. The averaged oxygen evolution geometric current density as a function of deposition time of (c) $\mathrm{NiOOH}$ at $400 \mathrm{mV}$ overpotential, (d) $\mathrm{NiFeOOH}$ at $300 \mathrm{mV}$ overpotential, and (e) $\mathrm{NiCeOOH}$ at $300 \mathrm{mV}$ overpotential. The highlighted areas signify the linear regime where the OER current density scales linearly with the deposition time. The lighter colors are for Au substrates, and darker colors are for GC substrates. The nonhighlighted areas were the plateau regime where the current density does not increase with increasing deposition time. 
Nine different loadings of three $\mathrm{NiOOH}$-based catalysts, $\mathrm{NiOOH}, \mathrm{NiFeOOH}$, and $\mathrm{NiCeOOH}$, were prepared by cathodic electrodeposition on GC and Au substrates (Figure S2). The first CV cycles of the catalysts deposited for $10 \mathrm{~s}$ are presented in Figure 1a and the overpotentials required to reach $10 \mathrm{~mA} / \mathrm{cm}^{2}$ for catalysts with varying loading are shown in Figure $1 \mathrm{~b}$. At $10 \mathrm{~mA} / \mathrm{cm}^{2}$, the OER activities of the samples are ordered as follows: $\mathrm{NiOOH} / \mathrm{GC}<\mathrm{NiOOH} / \mathrm{Au}<\mathrm{NiCeOOH} / \mathrm{GC}$ $\ll \mathrm{NiFeOOH} / \mathrm{GC} \leq \mathrm{NiFeOOH} / \mathrm{Au} \leq \mathrm{NiCeOOH} / \mathrm{Au}$. To reach $10 \mathrm{~mA} / \mathrm{cm}^{2}$, the most active catalysts were $20 \mathrm{~s}$ deposited $\mathrm{NiCeOOH} / \mathrm{Au}$ and $25 \mathrm{~s}$ deposited $\mathrm{NiFeOOH} / \mathrm{Au}$, requiring overpotentials as low as $259 \mathrm{mV}$ and $267 \mathrm{mV}$, respectively (Figure 1b). At higher overpotentials, $\mathrm{NiFeOOH} / \mathrm{Au}$ exhibits the highest activity due to its smaller Tafel slope of $39 \pm 2 \mathrm{mV} / \mathrm{dec}$ compared to $90 \pm 3 \mathrm{mV} / \mathrm{dec}$ of $\mathrm{NiCeOOH} / \mathrm{Au}$ (Figure S3). An average measured value of 140 $\mathrm{mA} / \mathrm{cm}^{2}$ was achieved by $30 \mathrm{~s}$ deposited $\mathrm{NiFeOOH}$ on a flat $\mathrm{Au}$ surface at $300 \mathrm{mV}$ overpotential in $1 \mathrm{M} \mathrm{NaOH}$. This performance is one of the highest OER activities reported for a catalyst synthesized on a planar support (Figure 1d). ${ }^{9}, 14$

These activities demonstrate that a Au substrate is advantageous compared to a GC substrate in regard to the geometric activity of the NiOOH-based OER catalysts prepared by cathodic deposition, as expected from previous studies. ${ }^{19}$ Interestingly, the enhanced activity was more pronounced at high loadings (greater than $500 \mathrm{nmol} / \mathrm{cm}^{2}$ ), as shown in the geometric current density plots of $\mathrm{NiOOH}, \mathrm{NiFeOOH}$, and $\mathrm{NiCeOOH}$ at overpotentials of $400 \mathrm{mV}, 300 \mathrm{mV}$, and $300 \mathrm{mV}$, respectively (Figure 1c-e). Up to a 6-fold increase in geometric current density was achieved by $\mathrm{NiCeOOH} / \mathrm{Au}$ compared to $\mathrm{NiCeOOH/GC}$.

The catalyst activities can be categorized into two regimes: the linear regime at low loadings where the activity scales linearly with the deposition time, and the plateau regime at higher loadings where the activity saturates. These linear regimes are highlighted in Figure 1c-e. The trend in 
geometric area normalized activity for the two substrates in the low loading regime is mostly similar for all catalysts; activities were mostly independent of substrate. However, the transition to the plateau regime on Au substrates occurred much later compared to that on the GC substrates. This leads to a considerably higher activity on Au substrates at high loadings. We note that the geometric activity is highly dependent on the true loading of the catalysts, which can vary drastically between samples, especially at very high loadings. In order to gain deeper insights into the role of the substrate, we proceed forward by investigating the turnover frequency (TOF) normalizing activity to the total number of metal sites, a relevant metric for the intrinsic activity.
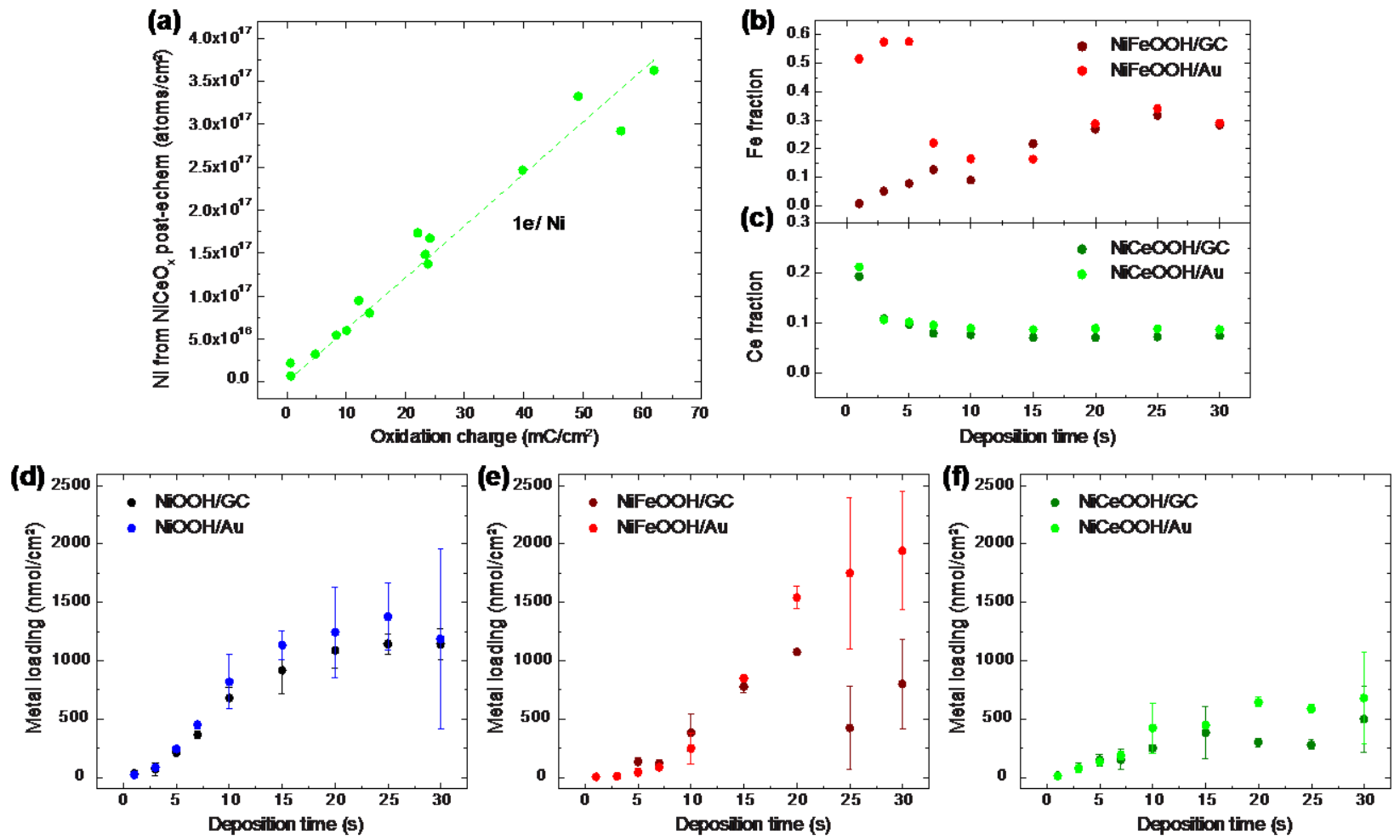

Figure 2. (a) The numbers of Ni atoms measured by ICP-OES on post-electrochemically tested $\mathrm{NiCeOOH}$ samples scale linearly with the charge integrated from the oxidation peak of $\mathrm{Ni}^{2+/ 3+}$

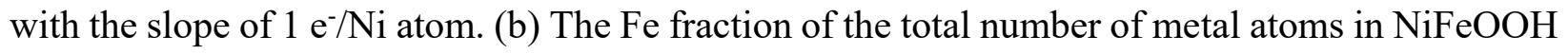
and (c) the Ce fraction of the total number of metal atoms in $\mathrm{NiCeOOH}$ vary slightly with the 
deposition time. Using the oxidation charge and ICP composition, the apparent metal loadings of (d) $\mathrm{NiOOH}$, (e) $\mathrm{NiFeOOH}$, and (f) $\mathrm{NiCeOOH}$ can be calculated.

\subsection{Catalyst Loading Quantification and Substrate Effects on TOF}

For the purpose of this discussion, we compare catalyst activity based on a turnover frequency (TOF all-metal) that is defined such that all metal sites loaded onto the electrode contribute equally to the current. To calculate the $\mathrm{TOF}_{\text {all-metal }}$ of the catalysts, the actual metal loading must be quantified. Using ICP-OES, the metal loadings and the Ce and Fe fractions can be measured as a function of the deposition time (Figure S4). The total amount of metal loadings ( $\mathrm{Ni}, \mathrm{Fe}, \mathrm{Ce}$ ) in the as-deposited films was independent of substrate. The amount of metal deposited scaled mostly linearly with the amount of charge passed during the deposition. Depending on the catalysts, the deposition efficiencies were 87-100\% (Figure S4a). However, the post-electrochemical testing samples exhibited much lower metal loading than the as-deposited samples, especially in the case of high loading catalysts (Figure S4b). This implies that not all the deposited catalyst remained physically attached during the electrochemical testing. To quantify the true loading, which is the amount of catalyst that was physically adhered and electrically connected to the substrate, the number of $\mathrm{Ni}$ atoms can be calculated from the $\mathrm{Ni}^{2+13+}$ oxidation peak in the first $\mathrm{CV}$ cycle of the freshly deposited sample. These oxidation charges were found to track well with the amount of $\mathrm{Ni}$ in $\mathrm{NiCeOOH}$ post-electrochemically tested as measured by ICP-OES, with one transferred

electron corresponding to one $\mathrm{Ni}$ atom, which is in excellent agreement with previous reports ${ }^{22,40}$ (Figure 2a).

Another critical parameter obtained from ICP-OES is the composition of the films. Figure $2 b$ shows that Fe preferentially deposits on Au vs GC substrates, making the first portions of the 
deposited film, closest to the Au substrate, to be Fe-rich up to $60 \%$ in composition. However, for depositions longer than $7 \mathrm{~s}$, the Fe composition reaches a similar fraction of $\sim 30 \%$ on both substrates. On the contrary, the composition of $\mathrm{NiCeOOH}$ seems to be independent of substrate and $10 \%$ Ce was observed in all films except the thinnest film of $1 \mathrm{~s}$ deposition, where up to $20 \%$ Ce was measured (Figure 2c). Unlike previous studies that reported drastic variations in $\mathrm{Fe}$ compositions in $\mathrm{NiFeOOH}$ films synthesized by a continuous cathodic deposition, ${ }^{22}$ our films exhibited low variation in metal compositions, possibly due to a deposition current that is much higher. This relatively constant metal composition helps to facilitate an even distribution of OER activity in our films and simplifies the intrinsic activity analysis. Using a combination of oxidation charge and the known compositions from ICP-OES, the true amounts of catalysts at different deposition times are shown in Figure 2d-f. It is apparent that using Au substrates results in higher catalyst loadings as compared to using GC substrates, especially at longer deposition times. This is likely a result of stronger physical adhesion and higher electrical connection of the catalysts on Au.

The $\mathrm{TOF}_{\text {all-metal }}$ values calculated from the geometric current densities and true catalyst loadings are shown in Figure 3a-c. We observed an initial decrease followed by a plateau in TOFall-metal as a function of deposition time which is similar to the trend observed by a previous study where the mass activity decreases as the catalyst transitions from the particle sintering regime to the constant intrinsic activity regime. ${ }^{15}$ Nevertheless, the physical adhesion cannot be the only source of enhanced activity. Figure 3d shows that after accounting for the loading differences, the intrinsic activities of $\mathrm{NiOOH}, \mathrm{NiFeOOH}$, and $\mathrm{NiCeOOH}$ on $\mathrm{Au}$ substrate exhibit non-negligible enhancement, especially at high loadings. Up to 3 times TOF all-metal improvement was achieved by both $\mathrm{NiFeOOH} / \mathrm{Au}$ and $\mathrm{NiCeOOH} / \mathrm{Au}$ over the GC substrates. 

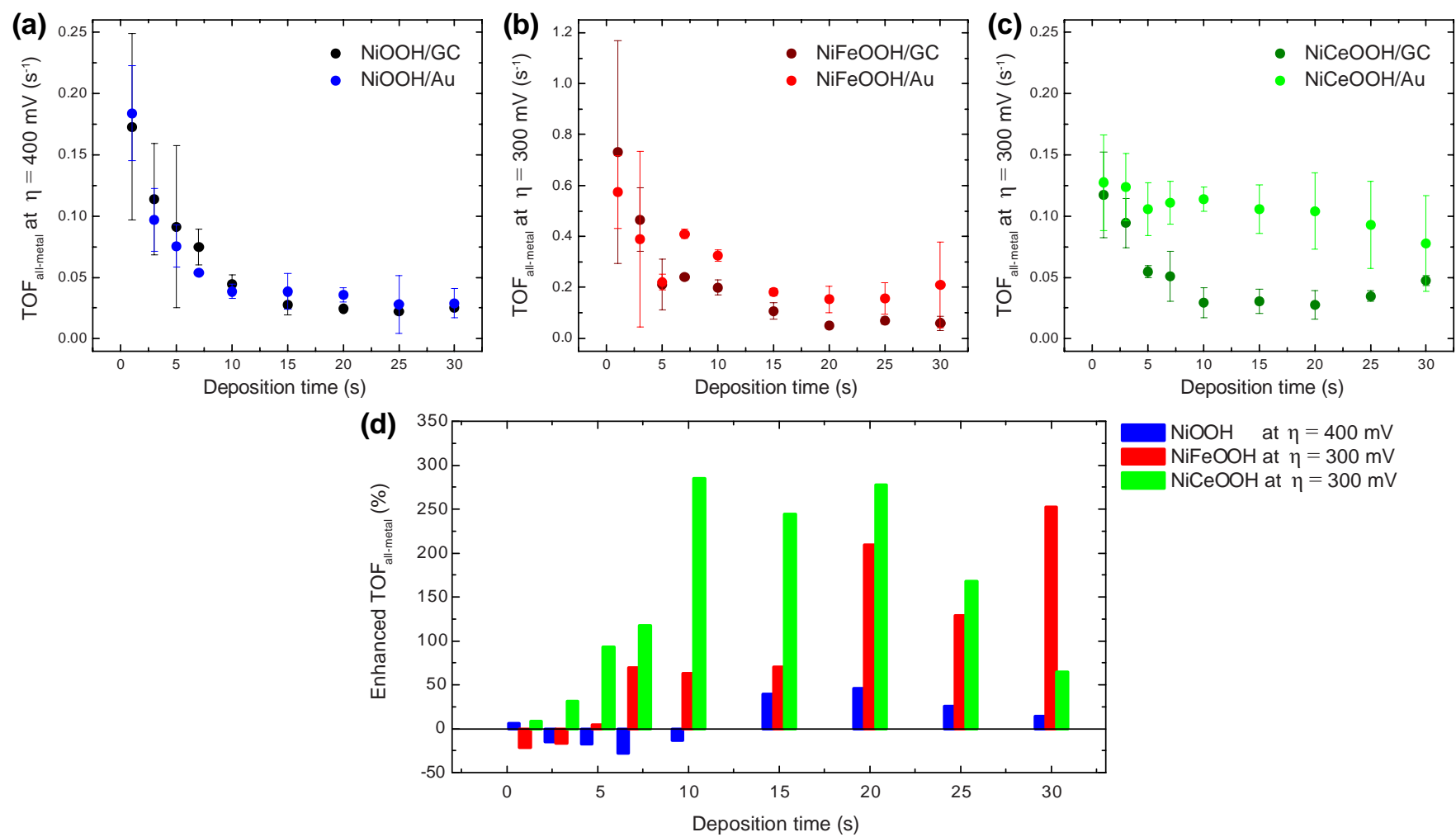

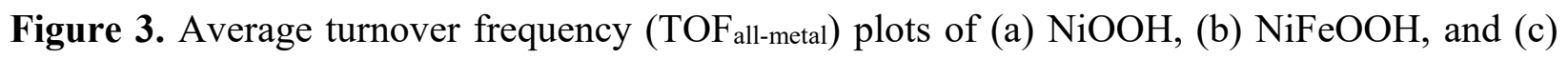
$\mathrm{NiCeOOH}$ at the specified overpotential ( $n$ ) calculated from the current densities and metal loadings from Figure 1 and 2. (d) The percentage increase in TOF all-metal of catalysts deposited on Au compared to GC substrate shows that Au slightly enhances the activity of $\mathrm{NiOOH}$ and only at high loadings for $\mathrm{NiFeOOH}$ but drastically improves the $\mathrm{NiCeOOH}$ activity for all loadings.

\subsection{Electrochemical and Physical Characterizations}

To investigate the origin of the enhanced activity by Au substrate, we further characterized all three catalyst systems. Without the applied potential, the catalysts are in an inactive reduced state of $\mathrm{Ni}^{2+}$, indicated by the transparency of the films by eye. In order to characterize the active films, in situ characterization techniques are required. 


\subsubsection{Electrochemical Impedance Spectroscopy (EIS)}

Using EIS, we investigated $\mathrm{NiOOH}, \mathrm{NiCeOOH}$, and $\mathrm{NiFeOOH}$ in their active states under an anodic applied bias. EIS allows us to get in situ information on, for example, the electrochemical surface area at OER relevant applied potentials. Figure 4a-b shows the Nyquist impedance spectra of various loadings of $\mathrm{NiCeOOH}$ on $\mathrm{Au}$ and GC substrates (see the Nyquist plots of $\mathrm{NiOOH}$ and $\mathrm{NiFeOOH}$ in Figure S5). For the ease of comparison, the electrolyte resistance $\left(R_{\mathrm{e}}\right)$ obtained at the high frequency was subtracted from each spectrum. Figure S6 shows the associated Bode plots of $\mathrm{NiCeOOH}$. All Nyquist plots exhibit one or two semicircular responses, inferring that up to two characteristic time constants can be extracted.

The equivalent circuit for OER impedance spectra proposed by previous studies ${ }^{41-44}$ and adopted by many OER studies is illustrated in Figure $4 c .{ }^{15,} 45$ The high frequency resistive response, $R$ e, represents the ohmic loss from electrolyte resistance. $Q_{\mathrm{dl}}$ and $\alpha_{\mathrm{dl}}$ are the components of a constant phase element (CPE) that represents a double layer capacitance $\left(C_{\mathrm{dl}}\right) . R_{\mathrm{p}}$ and $R_{\mathrm{s}}$ are connected to the kinetics of the interfacial charge transfer reaction. $Q_{\varnothing}$ and $\alpha_{\varnothing}$ are associated with the capacitive response caused by the absorbed intermediates. Lastly, $R_{\mathrm{f}}$ relates to the ohmic drop caused by the film resistivity or the electrolyte resistance drop due to porous morphology of the film, ${ }^{46}$ and the CPE components, $Q_{\mathrm{f}}$ and $\alpha_{\mathrm{f}}$, are associated with the dielectric properties of the oxide film. ${ }^{41}$ This equivalent circuit does not account for the effects of resistance loss as a function of the distance from the substrate. More complex equivalent circuits ${ }^{47-48}$ are required to extract the absolute values of the film resistances (see further discussion in the Supporting Information). The quantitative parameters extracted from the equivalent circuit in Figure $4 \mathrm{c}$ are meant to establish trends for comparison within the data set. 

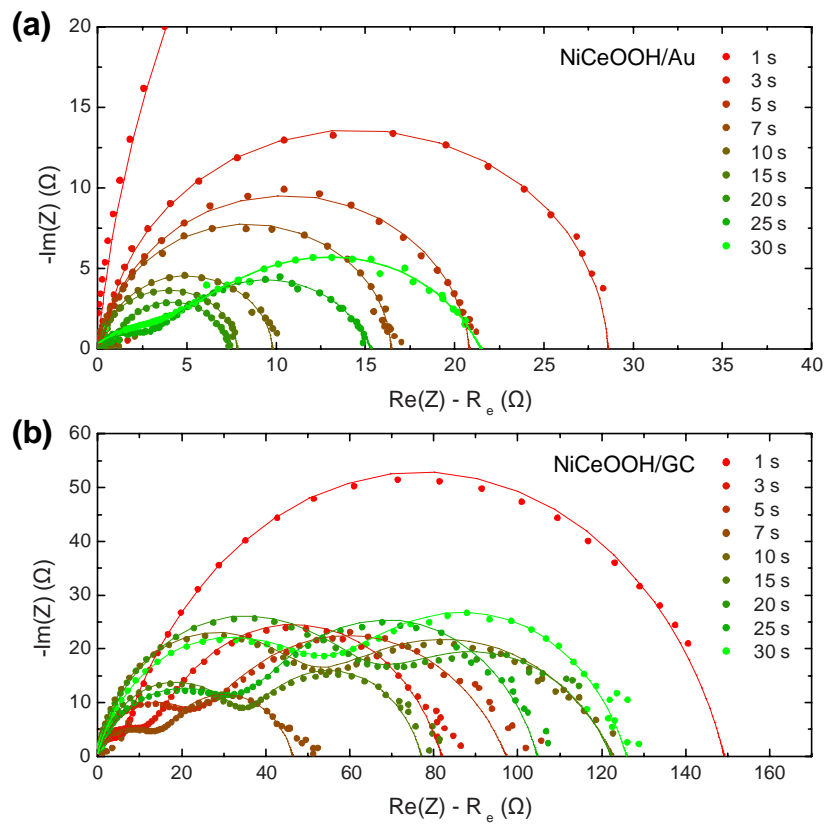

(c)

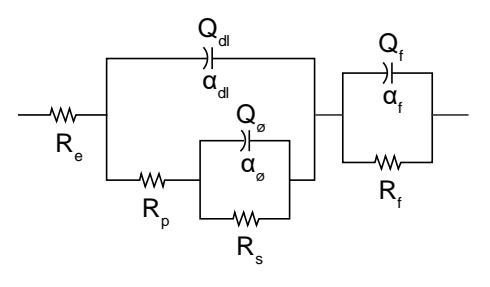

(d)

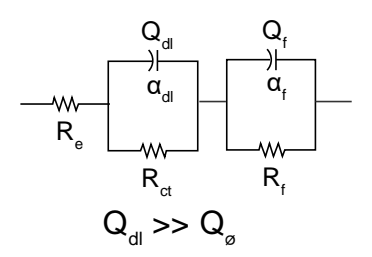

(e)

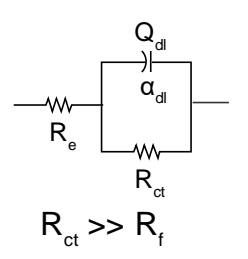

Figure 4. Nyquist plots of the (a) $\mathrm{NiCeOOH} / \mathrm{Au}$ and (b) $\mathrm{NiCeOOH} / \mathrm{GC}$ impedance spectra at varying deposition times. The symbols represent raw data, and the lines are the simulated spectra. For ease of comparison, the electrolyte resistance $\left(R_{\mathrm{e}}\right)$ was subtracted from the total impedance. (c) Equivalent circuit representing OER impedance. (d) Simplified model to Voigt circuit, assuming minimal effect of adsorption and desorption of intermediates. (e) The model can be reduced further to the Randles circuit by assuming no potential drop along the through-plane direction of the catalyst. 
Figure $4 \mathrm{c}$ circuit represents an impedance spectrum with three characteristic time constants $(\tau=$ RC),${ }^{49}$ which was not observed in our experiment. The model can be reduced to a Voigt circuit with two characteristic time constants by assuming $Q_{\phi} \ll<Q_{\mathrm{dl}}$ which takes place when there is negligible change in intermediate coverage due to the AC signal (Figure $4 \mathrm{~d}$ ) ${ }^{41}$ This is a reasonable assumption because the applied potential during EIS measurement was relatively high; hence, the $R_{\mathrm{p}}$ and $R_{\mathrm{s}}$ are replaced with a combined charge transfer resistance, $R_{\mathrm{ct}}$. Lastly, the model can be reduced further to a Randles circuit by assuming $R_{\mathrm{f}} \ll<R_{\mathrm{ct}}$. This is true in the case of an ideal catalyst that has a negligible resistance loss in the film layer (Figure 4e) ${ }^{41}$

The Nyquist spectra of the thin loading of $\mathrm{NiCeOOH} / \mathrm{Au}$ in Figure 4a show one semicircular response, inferring one characteristic time constant which is a result of the faradaic process of OER. Due to the thin and conductive catalyst, minimal potential drop occurs in the catalyst layer (negligible $R_{\mathrm{f}}$ ). Thus, the Randles circuit is representative of these spectra. On the other hand, in the higher loading films, i.e. greater than $20 \mathrm{~s}$ deposition, two semicircle profiles are observed, which signifies two time constants were present in the spectra. The second semicircle at high frequency arises from the catalyst film itself, and spectra can be described by the Voigt model. In the case of $\mathrm{NiCeOOH} / \mathrm{GC}$, two time constants were present in all spectra regardless of the catalyst loading (Figure 4b). Similar trends were found in $\mathrm{NiOOH}$ and $\mathrm{NiFeOOH}$ systems (Figure S5).

The fitted EIS parameters can be found in Figure S7. Three important parameters will be discussed in detail: $R_{\mathrm{f}}$ represents the ohmic loss in the catalyst layer, $R_{\mathrm{ct}}$ describes the rate of charge transfer and can be used to calculated an instantaneous Tafel slope, and $C_{\mathrm{dl}}$ relates to the electrochemical surface area. 

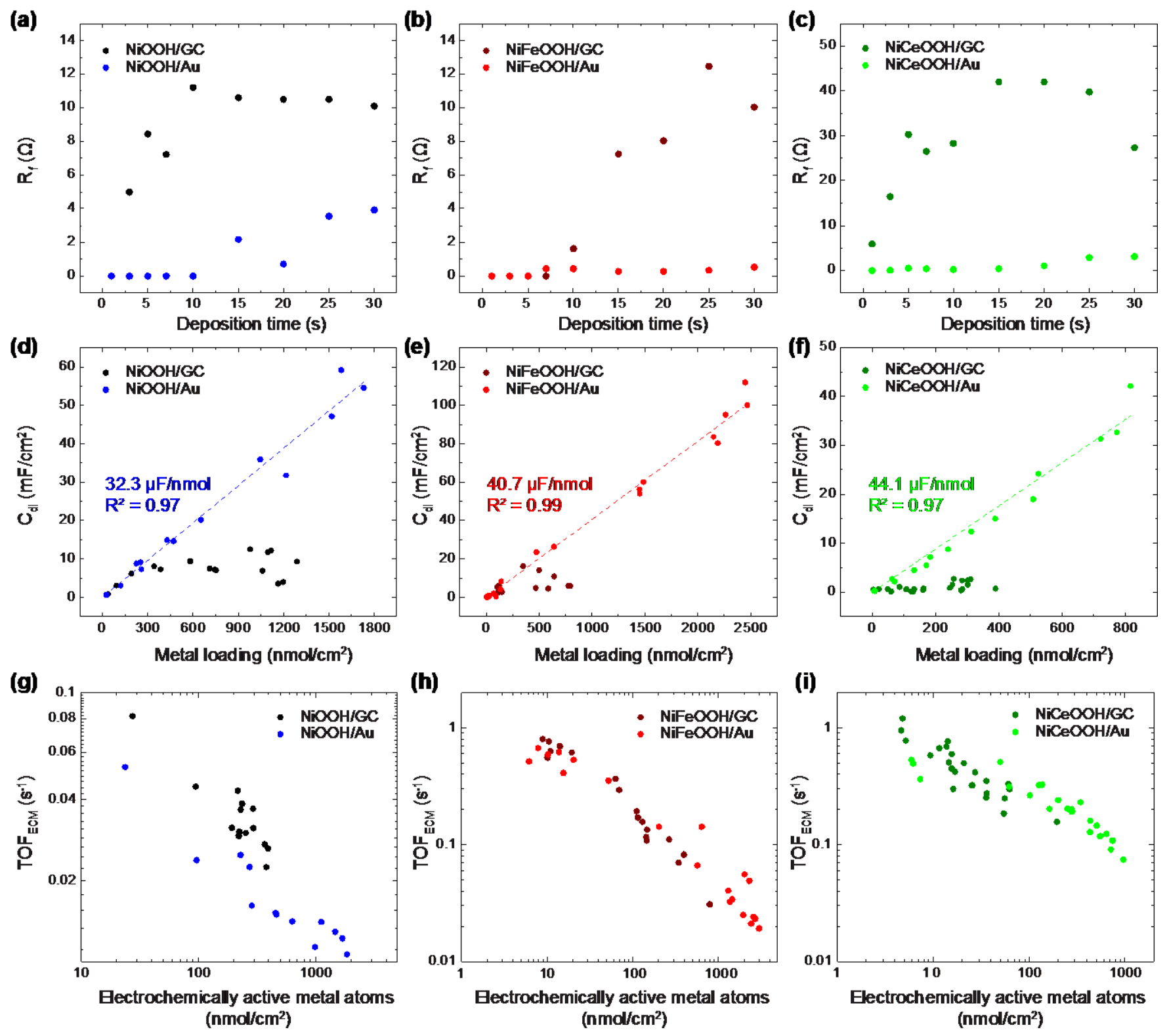

Figure 5. (a-c) $R_{\mathrm{f}}$ values obtained from the fitted EIS spectra of $\mathrm{NiOOH}, \mathrm{NiFeOOH}$, and $\mathrm{NiCeOOH}$ show much higher resistance on the GC substrates. (d-f) $C_{\mathrm{dl}}$ values of $\mathrm{NiOOH}$, $\mathrm{NiFeOOH}$, and $\mathrm{NiCeOOH}$ show that the $C_{\mathrm{dl}}$ values of GC samples do not linearly scale with metal loading. (g-i) Log-log plot of TOFЕСM (normalized to the electrochemically active metal sites) vs. electrochemically active metal calculated from $C_{\mathrm{dl}}$ and the current density measured during the EIS experiments of $\mathrm{NiOOH}$ (at $1.70 \mathrm{~V}$ ), $\mathrm{NiFeOOH}$ (at $1.55 \mathrm{~V}$ ), and $\mathrm{NiCeOOH}$ (at $1.60 \mathrm{~V}$ ), showing 
similar activity per electrochemically active metal site between catalysts deposited on Au and GC substrates.

The $R_{\mathrm{f}}$ values for all the catalysts deposited on Au and GC substrates share a similar trend, as shown in Figure 5a-c. On Au substrates, the $R_{\mathrm{f}}$ values of all of the catalysts were negligible in the films deposited for $10 \mathrm{~s}$ or shorter but became apparent in the thicker films. Nevertheless, the maximum resistance was less than $5 \Omega$ for $\mathrm{NiOOH} / \mathrm{Au}$ and $\mathrm{NiCeOOH} / \mathrm{Au}$, and it was lower than $1 \Omega$ for $\mathrm{NiFeOOH} / \mathrm{Au}$. On the other hand, the GC substrates exhibit much higher $R$ f, even at low loadings. The maximum $R_{\mathrm{f}}$ values of $\mathrm{NiOOH} / \mathrm{GC}$ and $\mathrm{NiFeOOH} / \mathrm{GC}$ were $10-15 \Omega$, while up to $45 \Omega$ was found on $\mathrm{NiCeOOH} / \mathrm{GC}$.

The $R \mathrm{f}$ values agree very well with the trend in Tafel slopes as shown in Figure S3c-d, which was extracted from the linear regime in the Tafel plots (see Figure S3a-b for the Tafel plots of $5 \mathrm{~s}$ deposited and $10 \mathrm{~s}$ deposited catalysts). The apparent Tafel slopes of the catalyst on Au remain relatively constant, but the Tafel slopes of the catalysts on GC substrates increase drastically with the catalyst loading. This change in apparent Tafel slopes could arise from the ohmic drop in the catalyst layer, which is not a characteristic of the OER kinetics. The kinetic Tafel slope can be calculated from $R_{\mathrm{ct}}$ using this expression: ${ }^{41}$

Tafel slope $=2.303 \mathrm{i} R_{\mathrm{ct}}$ 


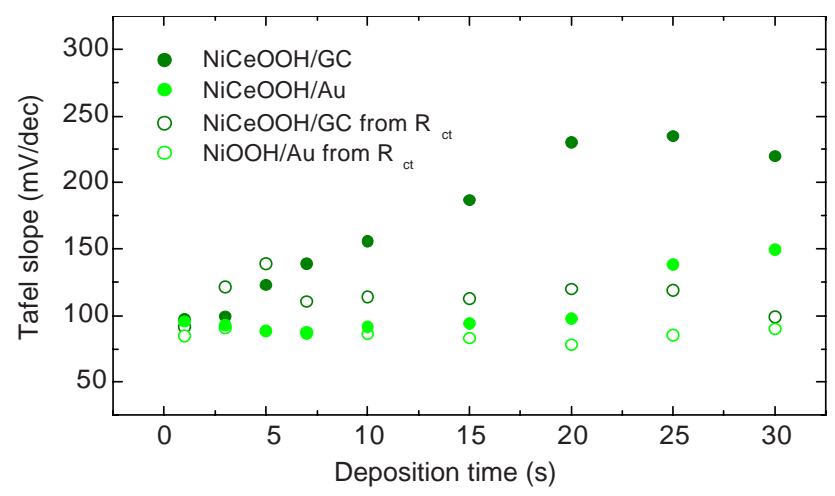

Figure 6. Tafel slopes calculated from the $\mathrm{CV}$ and $R_{\mathrm{ct}}$ values of $\mathrm{NiCeOOH}$ on $\mathrm{GC}$ and $\mathrm{Au}$ substrates.

Figure 6 shows that while the apparent Tafel slopes of NiCeOOH/GC varied drastically with the loading, the calculated kinetic Tafel slopes were mostly constant. This confirms that the change in the apparent Tafel slopes was not because of a change in reaction mechanism but rather from the ohmic loss due to the film resistivity. Film resistance is detrimental to the OER performance because the active sites located far away from the substrate will experience much lower applied potential. Hence, not all the metal sites were active during the electrochemical testing.

The loss in catalyst sites can be quantified by the $C_{\mathrm{dl}}$ extracted from the impedance spectra. The specific capacitance per metal loading can be obtained by plotting $C_{\mathrm{d} l}$ against the total metal loading calculated from the oxidation peak integration (Figure $5 \mathrm{~d}-\mathrm{f}$ ). $C_{\mathrm{dl}}$ of the catalysts deposited on Au scales linearly with the metal loading, demonstrating a specific capacitance of $32 \mu \mathrm{F} / \mathrm{nmol}$ of $\mathrm{Ni}$ in $\mathrm{NiOOH}, 41 \mu \mathrm{F} / \mathrm{nmol}$ of $\mathrm{Ni}$ and $\mathrm{Fe}$ in $\mathrm{NiFeOOH}$, and $44 \mu \mathrm{F} / \mathrm{nmol}$ of $\mathrm{Ni}$ and $\mathrm{Ce}$ in $\mathrm{NiCeOOH}$. On the contrary, the $C_{\mathrm{dl}}$ of the catalysts on GC substrates scales linearly with the amount of metal across only the low loading regime. The $C_{\mathrm{dl}}$ then reaches a plateau regime. The transitions from the linear regime to the plateau regime in $\mathrm{NiOOH} / \mathrm{GC}$ and $\mathrm{NiFeOOH} / \mathrm{GC}$ are at 
$300 \mathrm{nmol} / \mathrm{cm}^{2}$. This loading is equivalent to $\sim 200$ layers of $\mathrm{NiOOH}$ sheet, assuming a double layer hydroxide structure. Interestingly, the $C_{\mathrm{dl}}$ of $\mathrm{NiCeOOH} / \mathrm{GC}$ barely increases with the metal loading, showing an average capacitance of $1 \mathrm{mF} / \mathrm{cm}^{2}$, which corresponds to only $\sim 15$ layers of $\mathrm{NiOOH}$ sheet. Since the EIS measurement was performed at higher potentials than the $\mathrm{Ni}^{2+/ 3+}$ oxidation potential (at $1.70 \mathrm{~V}$ for $\mathrm{NiOOH}, 1.55 \mathrm{~V}$ for $\mathrm{NiFeOOH}$, and $1.60 \mathrm{~V}$ for $\mathrm{NiCeOOH}$ ), it is possible that the breakdown of the linear trend on GC substrates only take places at high potential and not all oxidized $\mathrm{Ni}$ atoms contribute to the $C_{\mathrm{dl}}$ at high potentials.

Using the $C_{\mathrm{dl}}$ values and the aforementioned specific capacitances obtained from the Au samples, we can obtain the amount of electrochemically active metal sites from each catalyst sample. The TOF per electrochemical active metal site (TOFECM) can be calculated from the EIS measurements in which both the OER current and the number of electrochemically active metal sites are measured, and the results are shown in Figure 5g-i. The $\log -\mathrm{TOF}$ ECM vs log-electrochemically active metal sites plots show linearly decreasing trends, nearly indistinguishable between Au or GC substrates. Within the error of the measurement, we can conclude that the intrinsic activities of the NiOOH-based catalysts at the investigated loadings are independent of substrate.

In our previous work on electrodeposited $\mathrm{NiCeOOH}$ films, where we had first reported a substantial enhancement in catalytic activity on Au compared to GC substrates, several possibilities for the origins of that enhancement were mentioned, in particular modifying the oxygen binding energy, improving film conductivity, and increasing the accessibility of catalytic sites. ${ }^{19}$ The results from this work show that the primary effect for enhanced activity on $\mathrm{Au}$ substrates, particularly in the high loading regime and observed in both the geometric activity as well as the $\mathrm{TOF}_{\text {all-metal, }}$ is predominantly caused by the lower film resistance and greater accessibility to electrochemically active sites. 
3.3.2 In Situ Chemical Characterization by C-ray Absorption Spectroscopy (XAS)

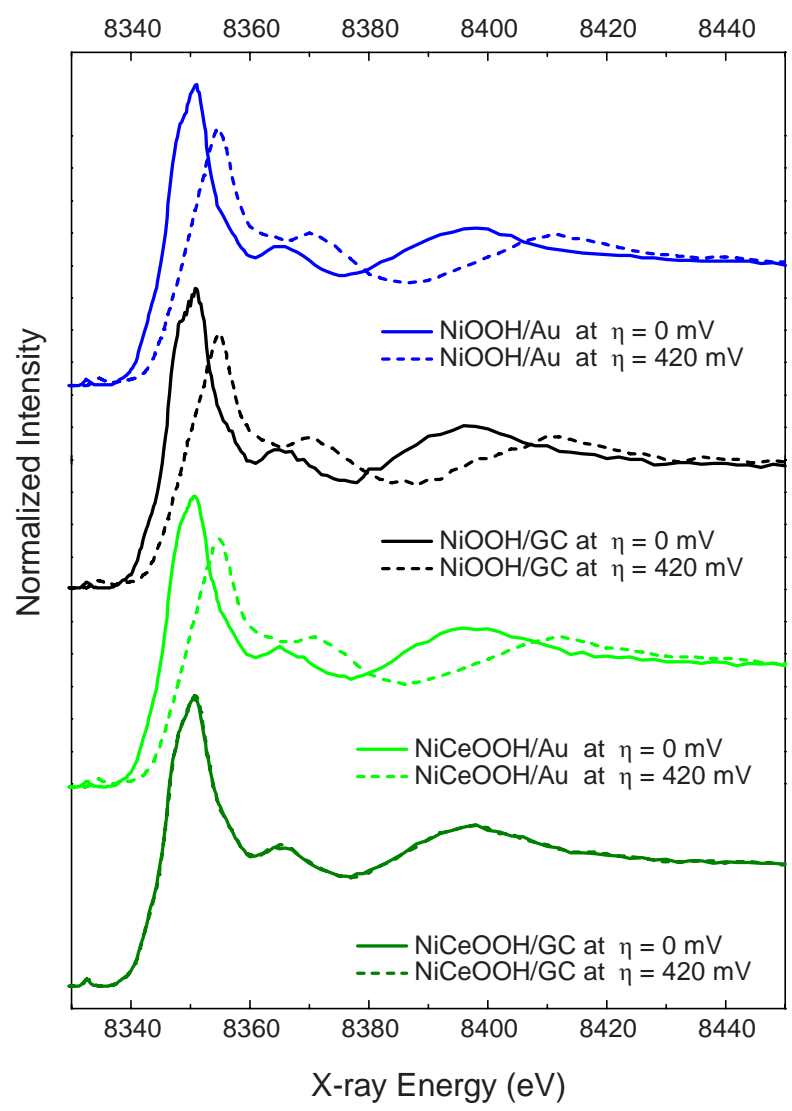

Figure 7. In situ XAS of $\mathrm{NiOOH}$ and $\mathrm{NiCeOOH}$ at 0 and $420 \mathrm{mV}$ overpotentials on $\mathrm{GC}$ and $\mathrm{Au}$ substrates. Unlike the $\mathrm{Ni}$ species in $\mathrm{NiOOH} / \mathrm{GC}, \mathrm{NiOOH} / \mathrm{Au}$, and $\mathrm{NiCeOOH} / \mathrm{Au}$, the majority of $\mathrm{Ni}$ in $\mathrm{NiCeOOH} / \mathrm{GC}$ did not get oxidized, resulting in low activity.

To further probe the catalyst system, the oxidation states of $\mathrm{NiOOH}$ and $\mathrm{NiCeOOH}$ on $\mathrm{Au}$ and GC substrates were investigated by in situ XAS. Samples of $1 \mathrm{~s}$ deposited $\mathrm{NiOOH}$ and $\mathrm{NiCeOOH}$ on GC and Au were subjected to varying applied bias from the thermodynamic OER potential to 420 $\mathrm{mV}$ overpotential. Figure 7 shows the XAS spectra at 0 and $420 \mathrm{mV}$ overpotentials of the Ni Kedge. At zero overpotential, $\alpha-\mathrm{Ni}(\mathrm{OH})_{2}$ similar to the as-deposited films was present. At $420 \mathrm{mV}$ overpotential, the $\mathrm{Ni}$ in $\mathrm{NiOOH} / \mathrm{GC}, \mathrm{NiOOH} / \mathrm{Au}$, and $\mathrm{NiCeOOH} / \mathrm{Au}$ became oxidized and appears 
to be in the $\gamma-\mathrm{NiOOH}$ phase. ${ }^{50}$ On the contrary, the Ni species within the investigated portion of the $\mathrm{NiCeOOH} / \mathrm{GC}$ sample remains at the $2+$ state at $420 \mathrm{mV}$ overpotential. This result has proven that there was a portion of catalyst in the $\mathrm{NiCeOOH} / \mathrm{GC}$ sample that did not experience the applied potential and remained inactive throughout the experiment, which agrees with our EIS analysis.

\subsubsection{Physical and Chemical Characterizations}
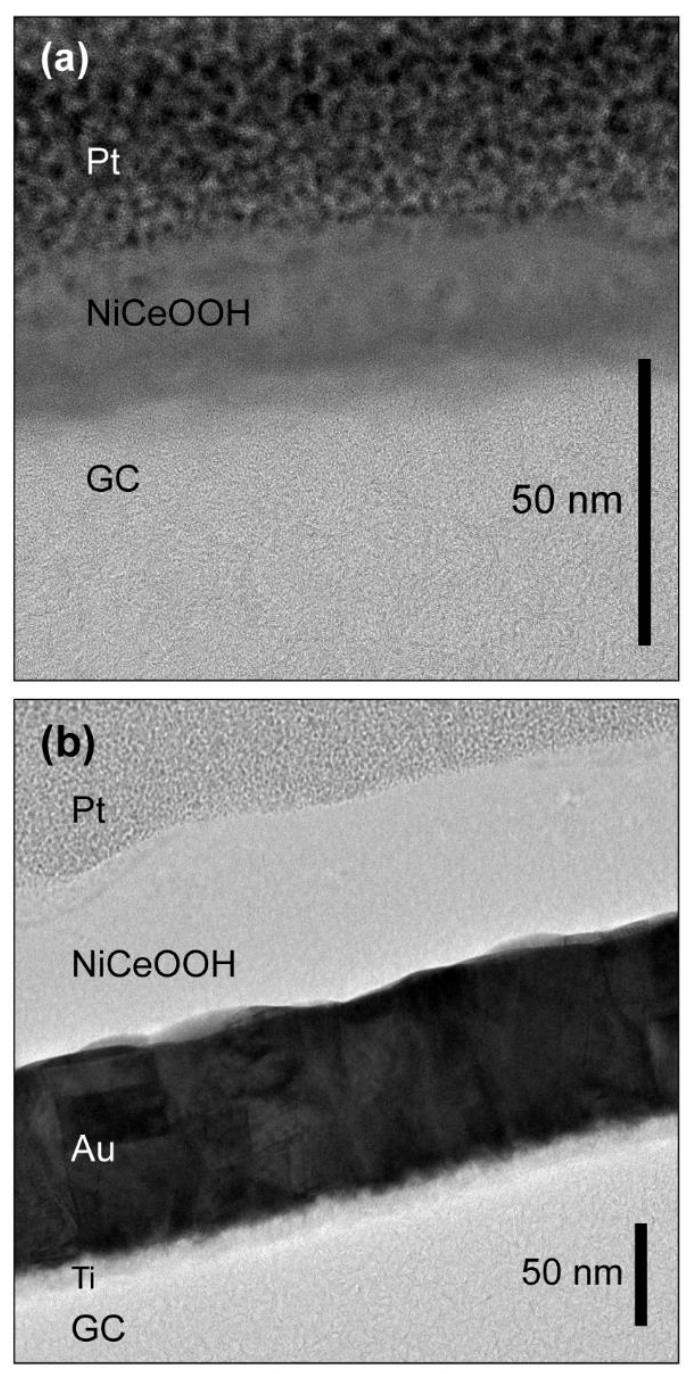

Figure 8. Cross-sectional TEM images of $10 \mathrm{~s}$ deposited (a) $\mathrm{NiCeOOH} / \mathrm{GC}$ and (b) $\mathrm{NiCeOOH} / \mathrm{Au}$ showing much thinner $\mathrm{NiCeOOH}$ layer on GC substrate, suggesting a highly nonhomogenous thickness which contributes to the high resistivity. 
The NiCeOOH samples were characterized by AFM which shows similar morphologies between the catalysts deposited on Au and GC (Figure S8). Both films also exhibit indistinguishable surface chemical compositions confirmed by XPS, similar to our previous work. ${ }^{19}$ The catalyst films did not show any XRD patterns. Cross-sectional TEM images of the as-prepared $\mathrm{NiCeOOH} / \mathrm{Au}$ show no detectable $\mathrm{Au}$ diffusion into the $\mathrm{NiCeOOH}$ layer. However, one major difference between $\mathrm{NiCeOOH} / \mathrm{Au}$ and $\mathrm{NiCeOOH} / \mathrm{GC}$ is the film thickness obtained from the cross-sectional TEM images. As shown in Figure 8, the thickness of $\mathrm{NiCeOOH}$ on $\mathrm{GC}$ is $\sim 26 \mathrm{~nm}$ while $\mathrm{NiCeOOH}$ on $\mathrm{Au}$ is $\sim 78 \mathrm{~nm}$. This large difference in thickness despite the similarity in loading as measured by the $\mathrm{Ni}^{2+/ 3+}$ oxidation peak could be caused by the nonhomogeneity on the GC surface, resulting in a nonuniform deposition of the catalyst. This hypothesis agrees well with the difference in the deposition potential between GC and Au substrates (Figure S1). The GC substrate required greater cathodic applied potential to reach $-16 \mathrm{~mA} / \mathrm{cm}^{2}$, which implies that the $\mathrm{GC}$ had a less electrochemically active surface compared to Au. The GC surface leads to a catalyst deposited with uneven thickness. The active sites located near the top of the thicker portions of the catalyst are expected to suffer from a high resistance drop. If the resistance is high enough, the catalyst might not reach a sufficiently anodic bias to drive the OER; hence, for uneven catalyst films the overall number of active sites that can participate in the reaction is lower than those for even catalyst films at the same loading. This hypothesis is confirmed by the in situ XAS data, which reveals that part of the $\mathrm{NiCeOOH} / \mathrm{GC}$ film did not get oxidized under a very positive applied potential. The uniform, electrically conductive, and unoxidized nature of Au increases the homogeneity in electrodeposition, resulting in catalysts with lower ohmic loss, higher electrochemically active sites, and better adhesion, which leads to higher geometric activity. 


\section{Conclusion}

We have systematically demonstrated that $\mathrm{Au}$ substrates enable $\mathrm{NiOOH}$-based catalysts to reach much higher geometric activities at high loadings compared to GC substrates. At low overpotential, $\mathrm{NiCeOOH} / \mathrm{Au}$ performed best with a loading of $\sim 650 \mathrm{nmol} / \mathrm{cm}^{2}$, requiring only 259 $\mathrm{mV}$ overpotential to achieve $10 \mathrm{~mA} / \mathrm{cm}^{2}$. At high potential, $\sim 1800 \mathrm{nmol} / \mathrm{cm}^{2}$ of NiFeOOH$/ \mathrm{Au}$ performed best due to the lower Tafel slope, achieving $140 \mathrm{~mA} / \mathrm{cm}^{2}$ with $300 \mathrm{mV}$. To investigate the origin of this enhanced activity, we first quantified the true catalyst loading using ICP-OES and $\mathrm{Ni}^{2+/ 3+}$ oxidation charge. ICP-OES not only verified that each oxidation charge integrated from the $\mathrm{Ni}^{2+/ 3+}$ peak corresponded to one $\mathrm{Ni}$ atom but also gave the accurate $\mathrm{Fe}$ and $\mathrm{Ce}$ composition as a function of loading. Loading quantification elucidated that higher amounts of catalysts remained on the Au substrates compared to GC substrates, but loading difference did not explain the higher $\mathrm{TOF}_{\text {all-metal }}$ found on Au samples at high loadings. EIS results uncovered that the biggest effect of using Au substrate is a lower film resistivity and a greater number of electrochemically active sites. This was identified by the linearly increasing double layer capacitances with increased loading of $\mathrm{NiOOH}$-based catalysts on $\mathrm{Au}$. On the contrary, the double layer capacitance did not increase beyond 200 layers of $\mathrm{NiOOH} / \mathrm{GC}$ and NiFeOOH/GC and only $\sim 15$ layers of NiCeOOH. This was later confirmed by in situ XAS, showing that NiCeOOH/GC contained a large amount of electrochemically inactive Ni species. Lastly, with cross-sectional TEM, we attributed the superior activity of $\mathrm{NiOOH}$-based catalysts on $\mathrm{Au}$ to a more homogeneous electrodeposition, resulting in conformal films with better adhesion, lower resistivity, and higher electrochemically active metal sites. This systematic method for investigating mass activity and site specific activity as a function of loading is a way to bridge an application relevant metric such as geometric activity to the 
fundamental understanding of intrinsic activity. This understanding is crucial to further engineer highly active OER catalysts for practical applications.

\section{ASSOCIATED CONTENT}

\section{Supporting Information.}

The Supporting Information is available free of charge on the ACS Publications website at DOI: 10.1021/acscatal.7b01070. The document consists of further detail on electrodeposition and electrochemical activity (Figure S1-S4), electrochemical impedance spectroscopy (Figure S5-7), and characterization by AFM (Figure S8). (PDF)

\section{AUTHOR INFORMATION}

\section{Corresponding Author}

*Email: jaramillo@stanford.edu

\section{ACKNOWLEDGMENT}

Primary support for this work was provided by the U.S. Department of Energy (DOE) Office of Science, Basic Energy Sciences to the SUNCAT Center for Interface Science and Catalysis. Use of the Stanford Synchrotron Radiation Lightsource, SLAC National Accelerator Laboratory, is supported by the U.S. Department of Energy, Office of Science, Office of Basic Energy Sciences under Contract No. DE-AC02-76SF00515. AG acknowledges the Department of Energy, Laboratory Directed Research and Development funding, under Contract No. DE-AC0276SF00515. The authors would like to thank Dr. Desmond Ng and David Mackanic for their help with initial experiments, Tom Carver for Au physical vapor depositions, and Roy Kim for his help with the sample preparation for TEM. Characterizations were performed in Stanford 
Nano Shared Facilities (SNSF) which receives support from the National Science Foundation

(NSF) through the National Nanotechnology Coordinated Infrastructure (NNCI) program.

The authors declare no competing financial interest.

\section{REFERENCES}

(1) Montoya, J. H.; Seitz, L. C.; Chakthranont, P.; Vojvodic, A.; Jaramillo, T. F.; Norskov, J. K. Nat. Mater. 2017, 16, 70-81.

(2) Lewis, N. S.; Nocera, D. G. Proc. Natl. Acad. Sci. U. S. A. 2006, 103, 15729-15735

(3) Ng, J. W. D.; Gorlin, Y.; Hatsukade, T.; Jaramillo, T. F. Adv. Energy Mater. 2013, 3, 15451550.

(4) Siahrostami, S.; Verdaguer-Casadevall, A.; Karamad, M.; Deiana, D.; Malacrida, P.;

Wickman, B.; Escudero-Escribano, M.; Paoli, E. A.; Frydendal, R.; Hansen, T. W.; Chorkendorff, I.; Stephens, I. E. L.; Rossmeisl, J. Nat. Mater. 2013, 12, 1137-1143.

(5) Bruce, P. G.; Freunberger, S. A.; Hardwick, L. J.; Tarascon, J.-M. Nat. Mater. 2012, 11, 1929.

(6) McCrory, C. C. L.; Jung, S.; Peters, J. C.; Jaramillo, T. F. J. Am. Chem. Soc. 2013, 135, 16977-16987.

(7) Ayers, K. E.; Anderson, E. B.; Capuano, C.; Carter, B.; Dalton, L.; Hanlon, G.; Manco, J.; Niedzwiecki, M. ECS Trans. 2010, 33, 3-15.

(8) Carmo, M.; Fritz, D. L.; Mergel, J.; Stolten, D. Int. J. Hydrogen Energy 2013, 38, 4901-4934.

(9) Dionigi, F.; Strasser, P. Adv. Energy Mater. 2016, 6, 1600621-n/a. 
(10) Lu, X.; Zhao, C. Nat. Commun. 2015, 6, 6616.

(11) Hong, W. T.; Risch, M.; Stoerzinger, K. A.; Grimaud, A.; Suntivich, J.; Shao-Horn, Y. Energy Environ. Sci. 2015, 8, 1404-1427.

(12) Man, I. C.; Su, H.-Y.; Calle-Vallejo, F.; Hansen, H. A.; Martínez, J. I.; Inoglu, N. G.; Kitchin, J.; Jaramillo, T. F.; Nørskov, J. K.; Rossmeisl, J. ChemCatChem 2011, 3, 1159-1165.

(13) Benck, J. D.; Hellstern, T. R.; Kibsgaard, J.; Chakthranont, P.; Jaramillo, T. F. ACS Catal. 2014, 4, 3957-3971.

(14) Seh, Z. W.; Kibsgaard, J.; Dickens, C. F.; Chorkendorff, I.; Nørskov, J. K.; Jaramillo, T. F. Science 2017, 355.

(15) Morales-Guio, C. G.; Liardet, L.; Hu, X. J. Am. Chem. Soc. 2016, 138, 8946-8957.

(16) Subbaraman, R.; Tripkovic, D.; Chang, K.-C.; Strmcnik, D.; Paulikas, A. P.; Hirunsit, P.; Chan, M.; Greeley, J.; Stamenkovic, V.; Markovic, N. M. Nat. Mater. 2012, 11, 550-557.

(17) Gong, M.; Dai, H. Nano Res. 2015, 8, 23-39.

(18) Corrigan, D. A.; Bendert, R. M. J. Electrochem. Soc. 1989, 136, 723-728.

(19) Ng, J. W. D.; García-Melchor, M.; Bajdich, M.; Chakthranont, P.; Kirk, C.; Vojvodic, A.; Jaramillo, T. F. Nat. Energy 2016, 1, 16053.

(20) Enman, L. J.; Burke, M. S.; Batchellor, A. S.; Boettcher, S. W. ACS Catal. 2016, 6, 24162423.

(21) Louie, M. W.; Bell, A. T. J. Am. Chem. Soc. 2013, 135, 12329-12337. 
(22) Batchellor, A. S.; Boettcher, S. W. ACS Catal. 2015, 5, 6680-6689.

(23) Klingan, K.; Ringleb, F.; Zaharieva, I.; Heidkamp, J.; Chernev, P.; Gonzalez-Flores, D.; Risch, M.; Fischer, A.; Dau, H. ChemSusChem 2014, 7, 1301-1310.

(24) Pérez-Alonso, F. J.; Adán, C.; Rojas, S.; Peña, M. A.; Fierro, J. L. G. Int. J. Hydrogen Energy 2014, 39, 5204-5212.

(25) Xu, Y.; Hao, Y.; Zhang, G.; Lu, Z.; Han, S.; Li, Y.; Sun, X. RSC Adv. 2015, 5, 5513155135.

(26) Benck, J. D.; Pinaud, B. A.; Gorlin, Y.; Jaramillo, T. F. PLoS One 2014, 9, e107942.

(27) Yeo, B. S.; Bell, A. T. J. Phys. Chem. C 2012, 116, 8394-8400.

(28) Burke, M. S.; Zou, S.; Enman, L. J.; Kellon, J. E.; Gabor, C. A.; Pledger, E.; Boettcher, S. W. J. Phys. Chem. Lett. 2015, 6, 3737-3742.

(29) Long, X.; Li, J.; Xiao, S.; Yan, K.; Wang, Z.; Chen, H.; Yang, S. Angew. Chem., Int. Ed. $2014,53,7584-7588$.

(30) Gong, M.; Li, Y.; Wang, H.; Liang, Y.; Wu, J. Z.; Zhou, J.; Wang, J.; Regier, T.; Wei, F.; Dai, H. J. Am. Chem. Soc. 2013, 135, 8452-8455.

(31) Yu, X.; Zhang, M.; Yuan, W.; Shi, G. J. Mater. Chem. A 2015, 3, 6921-6928.

(32) Klaus, S.; Cai, Y.; Louie, M. W.; Trotochaud, L.; Bell, A. T. J. Phys. Chem. C 2015, 119, 7243-7254.

(33) Yeo, B. S.; Bell, A. T. J. Am. Chem. Soc. 2011, 133, 5587-5593. 
(34) Zou, S.; Burke, M. S.; Kast, M. G.; Fan, J.; Danilovic, N.; Boettcher, S. W. Chem. Mater. 2015, 27, 8011-8020.

(35) Gorlin, Y.; Chung, C. J.; Benck, J. D.; Nordlund, D.; Seitz, L.; Weng, T. C.; Sokaras, D.; Clemens, B. M.; Jaramillo, T. F. J. Am. Chem. Soc. 2014, 136, 4920-4926.

(36) Seitz, L. C.; Hersbach, T. J. P.; Nordlund, D.; Jaramillo, T. F. J. Phys. Chem. Lett. 2015, 6, 4178-4183.

(37) Trotochaud, L.; Young, S. L.; Ranney, J. K.; Boettcher, S. W. J. Am. Chem. Soc. 2014, 136, 6744-6753.

(38) Lasia, A. Electrochemical impedance spectroscopy and its applications; Springer: 2014; pp $177-250$.

(39) Sokaras, D.; Weng, T.-C.; Nordlund, D.; Alonso-Mori, R.; Velikov, P.; Wenger, D.; Garachtchenko, A.; George, M.; Borzenets, V.; Johnson, B. Rev. Sci. Instrum. 2013, 84, 053102.

(40) Stevens, M. B.; Enman, L. J.; Batchellor, A. S.; Cosby, M. R.; Vise, A. E.; Trang, C. D. M.; Boettcher, S. W. Chem. Mater. 2017, 29, 120.

(41) Lyons, M. E.; Brandon, M. P. J. Electroanal. Chem. 2009, 631, 62-70.

(42) Doyle, R. L.; Godwin, I. J.; Brandon, M. P.; Lyons, M. E. G. Phys. Chem. Chem. Phys. $2013,15,13737-13783$.

(43) Doyle, R. L.; Lyons, M. E. G. Phys. Chem. Chem. Phys. 2013, 15, 5224-5237.

(44) Doyle, R. L.; Lyons, M. E. G. J. Electrochem. Soc. 2013, 160, H142-H154. 
(45) Swierk, J. R.; Klaus, S.; Trotochaud, L.; Bell, A. T.; Tilley, T. D. J. Phys. Chem. C 2015, 119, 19022-19029.

(46) Chen, L.; Lasia, A. J. Electrochem. Soc. 1993, 140, 2464-2473.

(47) Bisquert, J. J. Phys. Chem. B 2002, 106, 325-333.

(48) Bisquert, J.; Grätzel, M.; Wang, Q.; Fabregat-Santiago, F. J. Phys. Chem. B 2006, 110, 11284-11290.

(49) Orazem, M. E.; Tribollet, B. Electrochemical impedance spectroscopy; John Wiley \& Sons: 2011; Vol. 48, pp 233-264.

(50) Friebel, D.; Louie, M. W.; Bajdich, M.; Sanwald, K. E.; Cai, Y.; Wise, A. M.; Cheng, M.J.; Sokaras, D.; Weng, T.-C.; Alonso-Mori, R.; Davis, R. C.; Bargar, J. R.; Nørskov, J. K.; Nilsson, A.; Bell, A. T. J. Am. Chem. Soc. 2015, 137, 1305-1313. 


\section{TOC Graphic}

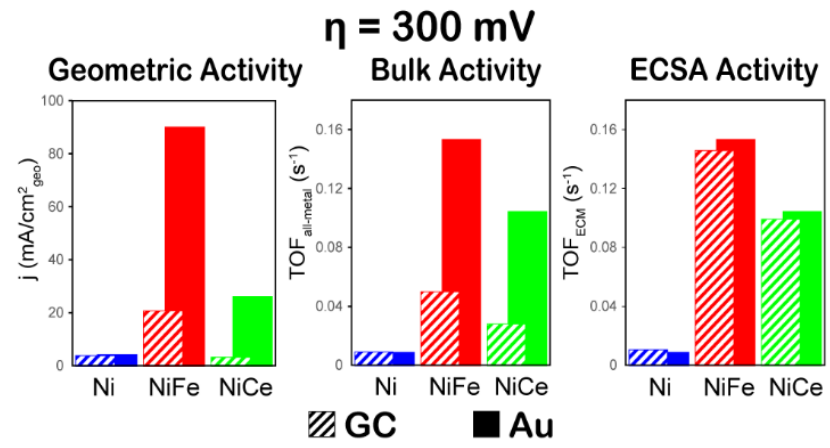

